\title{
Adverse events with COVID-19 vaccination among the health care professionals of Himachal Pradesh- A Rapid Survey
}

\section{Harshvardhan Singh ${ }^{1}$, Shailja Sharma ${ }^{2}$}

${ }^{1}$ Assistant Professor, Department of Community Medicine, Dr. Rajendra Prasad Government Medical College, Kangra, Tanda. Himachal Pradesh; ${ }^{2}$ Assistant Professor, Department of Community Medicine, Dr. Rajendra Prasad Government Medical College, Kangra, Tanda. Himachal Pradesh.

\begin{tabular}{|c|c|c|c|c|c|c|c|c|}
\hline Abstract & Introduction & Methodology & $\underline{\text { Results }}$ & Conclusion & $\underline{\text { References }}$ & $\underline{\text { Citation }}$ & \multicolumn{2}{|c|}{ Tables / Figures } \\
\hline \multicolumn{9}{|c|}{ Corresponding Author } \\
\hline \multicolumn{8}{|c|}{$\begin{array}{l}\text { Dr Shailja Sharma, Assistant Professor, Department of Community Medicine, Dr. Rajendra Prasad } \\
\text { Government Medical College, Kangra, Tanda. Himachal Pradesh } 176002 \\
\text { E Mail ID: drshailjasharmasood@gmail.com }\end{array}$} & 回的回 \\
\hline
\end{tabular}

\section{Citation}

Singh H, Sharma S. Adverse events with COVID-19 vaccination among the health care professionals of Himachal Pradesha Rapid Survey. Indian J Comm Health. 2021;33(3):531-533. https://doi.org/10.47203/IJCH.2021.v33i03.023

Source of Funding: Nil Conflict of Interest: None declared

\section{Article Cycle}

Received: 01/06/2021; Revision: 07/08/2021; Accepted: 29/09/2021; Published: 30/09/2021

This work is licensed under a Creative Commons Attribution 4.0 International License.

\section{Abstract}

Background: The rolling out of the COVID -19 vaccination programme was accompanied by several doubts including the safety and occurrence of adverse effects after the vaccination. Methodology: A cross sectional study was conducted amongst the health care professionals working in the state of Himachal Pradesh to assess the frequency and types of side effects associated with the administration of Covid-19 vaccines using a semi structured questionnaire floated through a Google form. Result: Of the 187 responses received, after the $1^{\text {st }}$ dose, $37.5 \%$ participants reported malaise, $31 \%$ myalgia, $36.4 \%$ low-grade fever, while $18.5 \%$ high-grade fever. Mild reactions at the injection site were reported by $37.5 \%$, headache was reported by $3 \%$, low back ache, drowsiness, giddiness and diarrhea were reported by about $3 \%$. No reactions were reported by $18.5 \%$ of the participants. After the second dose, 51.8\% did not report any adverse event, $17.1 \%$ reported malaise,15.2\% reported low grade fever, 3\% reported high grade fever, $20.1 \%$ reported mild reactions at the site of injection while $4.2 \%$ reported drowsiness, breathlessness on exertion, nausea, low back ache and diarrhea. Conclusion: The frequency of adverse events with COVID -19 vaccines is not higher than those observed with other commonly used vaccines.

\section{Keywords}

AEFI; COVID-19; Vaccines

\section{Introduction}

The advent of the novel coronavirus left the health care system across the world cringing under the large burden of patients. With no treatment or vaccine in place, the year 2020 saw massive efforts directed towards vaccine development. Vaccination is a crucial component of an effective global pandemic response.(1) Two vaccine candidates Covishield (ChAdOx1) \& Covaxin (BBV152) applied for approval in about one year's time and were granted approval in India by January 2021. The method of development of these vaccines has consistently been under the scanner due to the short time in which they were developed and issues related to data transparency and emergency use approval etc. There is limited literature at the national and subnational level giving information about such adverse events following vaccination for COVID -19.

\section{Aim \& Objective}

To study the AEFIs with COVID-19 vaccines.

\section{Material \& Methods}

A cross sectional study was conducted amongst the health care professionals working in the state of Himachal Pradesh, serving in the government as well as the private sector. All such health care professionals who had received at least one dose of either of the two available vaccines (ChAdOx1 \& BBV152) and had consented to participate were included in the study.

Considering the prevalence of minor adverse events from Covishield (ChAdOx1) to be approximately 15\% (2), population of health care workers in the state to be approximately 7000, a sample size of 210 was calculated at an allowable error of $5 \%$ and a confidence interval of $95 \%$. 
A semi structured questionnaire containing questions regarding the date of vaccination, the brand name of the vaccine, the type of adverse event if any, as well as questions regarding age, gender and place of work, was floated as a google form on all the social media platforms. The questionnaire also contained a consent form, as well as a statement ensuring the confidentiality of the participant. The participants were contacted through Email, telephone and WhatsApp, urging them to participate in the survey. The process continued till the required sample size was achieved. Data collection was completed in about 5 days, after which the data was analysed using Microsoft Excel. Ethical clearance for the study has been received from the Institutional Ethics committee.

\section{Results}

A total of 216 responses to the questionnaire were received over a period of five days. Of these 29 were not valid as they had not received vaccination. Therefore 187 responses were analyzed. All the participants had received Covishield (ChAdOx1) vaccine only.

Of the 187 responses received, 37.5\% participants experienced malaise, 31\% experienced myalgias, $36.4 \%$ experienced low-grade fever, while $18.5 \%$ experienced high-grade fever after the 1 st dose. Mild reactions at the injection site were reported by $37.5 \%$, headache was reported by $3 \%$, while several other adverse effects including low back ache, drowsiness, giddiness and diarrhea were reported by about $3 \%$ of the participants after the first dose. No reactions were reported by approximately $18.5 \%$ of the participants after the first dose.(Figure 1)

After receiving the second dose, $51.8 \%$ participants did not report any adverse event. However $17.1 \%$ did report malaise while $15.2 \%$ reported low grade fever. High grade fever was seen in only $3 \%$ of the participants while mild reactions at the site of injection were reported by $20.1 \%$ of the participants. Mild events such as drowsiness, breathlessness on exertion, nausea, low back ache and diarrhea were reported by approximately $4.2 \%$ of the respondents. (Figure 1)

No severe reactions such as anaphylaxis and toxic shock syndrome were reported after vaccination.

Approximately $92.9 \%$ were overall satisfied with the services and management at the vaccination site.

In response to the section inviting suggestions, $64 \%$ the participants suggested ramping up the IEC activities with major focus on busting all the myths regarding vaccination, $23 \%$ suggested involving the private sector in this vaccination drive while $21 \%$ suggested opening up of more vaccination centers to avoid crowding.

\section{Discussion}

\section{The findings of the current study}

There were more adverse effects after the first dose of vaccination as compared to the second dose with approximately $81.5 \%$ people reporting an event after their 1st dose. Majority of the participants (37.5\%) reported malaise, low grade fever (36.4\%), mild reaction at the injection site (37.5\%) and myalgia (31\%).

The second dose saw fewer reports of adverse reactions as $51.8 \%$ reported having experienced no adverse event. Most commonly observed reactions after the second dose were malaise (17.1\%) mild reactions at the injection site (20.1\%) and low-grade fever (15.2\%).

No serious events were reported.(Figure 1)

\section{Comparison to other common vaccines}

Adverse reactions are not new to vaccinations, as previously used vaccines have also triggered such events ranging from mild fever and pain at the injection site to severe life threatening events.(3) Vaccine against Diphtheria is a toxoid which is a part of the National immunization programme in India and is used widely across the world. The vaccine is known to trigger low grade fever in approximately $40-75 \%$ of the beneficiaries. Pain at the site (50\%) and drowsiness in 33-62\% beneficiaries have been reported. Amongst the severe events hypotonic/hypo responsive episodes (0.29\%) and febrile seizures $(0.008 \%)$ too have been reported although rare.(4) Influenza vaccination has also seen low grade fever (5-12\%),myalgia, malaise and pain at the injection site. A very rare occurrence of GBS has also been reported with this vaccine $(0.0001 \%)$.(5) Measles vaccination has reported fever in 5-15\% of beneficiaries and rashes in $2 \%$ of the beneficiaries. Severe adverse events such as anaphylaxis, febrile seizures, transient thrombocytopenia and SSPE have been reported $(0.0035 \%-0.086 \%)$ though rare.(6) Vaccination with PCV has also seen pain at the injection site (41-55\%) and fever (30-40\%)as the major adverse events among the beneficiaries.(7)

The most frequent adverse events observed in the present study, i.e. pain and mild reactions at the site of injection are lesser than similar events reported after Diphtheria and PCV vaccination. Fever during COVID vaccination is the other most frequent event reported in the present study, however the frequency of occurrence of fever after vaccination with COVID is also lesser as compared to that with diphtheria and PCV vaccines. Malaise and myalgias reported during COVID vaccination have been reported with flu vaccines too. With administration of Diphtheria and Measles generally to children, myalgia or malaise are not likely to be reported. (Table 1)

High grade fever reported (18.5\%) after COVID vaccination has been successfully managed with treatment and rest, with no residual deficit.

\section{Conclusion}

The spectrum and frequency of adverse events observed with COVID-19 vaccines is similar to other vaccines.

\section{Recommendation}

The study therefore reinforces the claim that the COVID 19 vaccines are safe in adults, laying to rest all apprehensions regarding their safety. 


\section{Limitation of the study}

Being an institutional setup, some observations could have been missed due to absence of real time reporting and there may be possible observation and reporting biases, as the respondents were HCW.

\section{Relevance of the study}

This study was conceptualized with an intent to generate reliable local data from $\mathrm{HCW}$ that could add up to evidence regarding adverse events and provide impetus to the ongoing vaccination drive.

\section{Authors Contribution}

Both authors contributed equally.

\section{References}

1. Hung IFN, Poland GA. Single-dose Oxford-AstraZeneca COVID-19 vaccine followed by a 12-week booster. The Lancet. 2021; 397(10277): 855. Available from: https://doi.org/10.1016/S01406736(21)00528-6. [Last accessed on 25.09.21]

2. Serum Institute of India Limited. ChAdOx1 nCoV- 19 Corona Virus Vaccine (Recombinant) fact sheet. Available from: https://www.seruminstitute.com/product covishield.php . [Last accessed on 25.09.21]

3. World Health Organisation. Vaccine safety basics learning manual $2013 . \quad$ Available from: https://www.who.int/vaccine_safety/initiative/tech_support/Part -3.pdf?ua=1 [Last accessed on 25.09.21]

4. World Health Organisation. Diphtheria position paper 2017. Available from: https://www.who.int/immunization/policy/position_papers/dipht heria/en/ [Last accessed on 25.09.21]

5. World Health Organisation. Vaccines against Influenza. WHO position paper- November, 2017. Available from: https://www.who.int/wer/2012/wer8747.pdf?ua=1 [Last accessed on 25.09.21]

6. World Health Organisation. Measles vaccines: WHO position paper - April $2017 . \quad$ Available from: https://www.who.int/publications/i/item/measles-vaccines-whoposition-paper-april-2017 [Last accessed on 25.09.21]

7. World Health Organisation. WHO position paper on Pneumococcal conjugate vaccines. Available from: https://www.who.int/immunization/programmes systems/procu rement/mi4a/platform/module2/Pneumococcal Vaccine_Market Study-June2020.pdf?ua=1 [Last accessed on 25.09.21]

Tables

TABLE 1 COMPARISON BETWEEN ADVERSE EFFECTS REPORTED WITH DIFFERENT VACCINES.

\begin{tabular}{|c|c|c|c|c|c|}
\hline Adverse reaction & Covid-19 (current study) & Measles & Diphtheria & PCV & Influenza \\
\hline Pain on site & 37.5 & + & $50 \%$ & $41 \%-55 \%$ & $>0.01 \%$ \\
\hline Fever & 36.4 & $5-15 \%$ & $40-75 \%$ & $30 \%-40 \%$ & + \\
\hline High grade fever & 18.5 & & $0.3 \%$ & $2.2 \%-3.9 \%$ & \\
\hline Malaise & 37.5 & & & & + \\
\hline Myalgia & 31 & & & & + \\
\hline Drowsiness & 3.8 & & $33-62 \%$ & & \\
\hline Loss of appetite & Nil & & $20-35 \%$ & & \\
\hline Vomiting & Nil & & $6-13 \%$ & & \\
\hline Rash & Nil & $2 \%$ & & & \\
\hline Hypotonic- hyporesponsive episodes & & & $0.29 \%$ & & \\
\hline Anaphylactic reactions & 1.1 & $.00035 \%-0.001 \%$ & & & \\
\hline Febrile seizures & Nil & $0.034-0.086 \%$ & $0.008 \%$ & & \\
\hline Transient thrombocytopenia & Nil & $0.003 \%-0.004 \%$ & & & \\
\hline Toxic shock syndrome & 1.1 & & & & \\
\hline \multicolumn{6}{|l|}{ septicaemia, } \\
\hline Fatal events & & Rare & & & \\
\hline Kawasaki disease & & & & Rare & \\
\hline GBS & & & & & $0.0001 \%$ \\
\hline
\end{tabular}

Figures

FIGURE 1 ADVERSE EVENTS EXPERIENCED AFTER 1ST AND 2ND DOSE OF COVID-19 VACCINE.

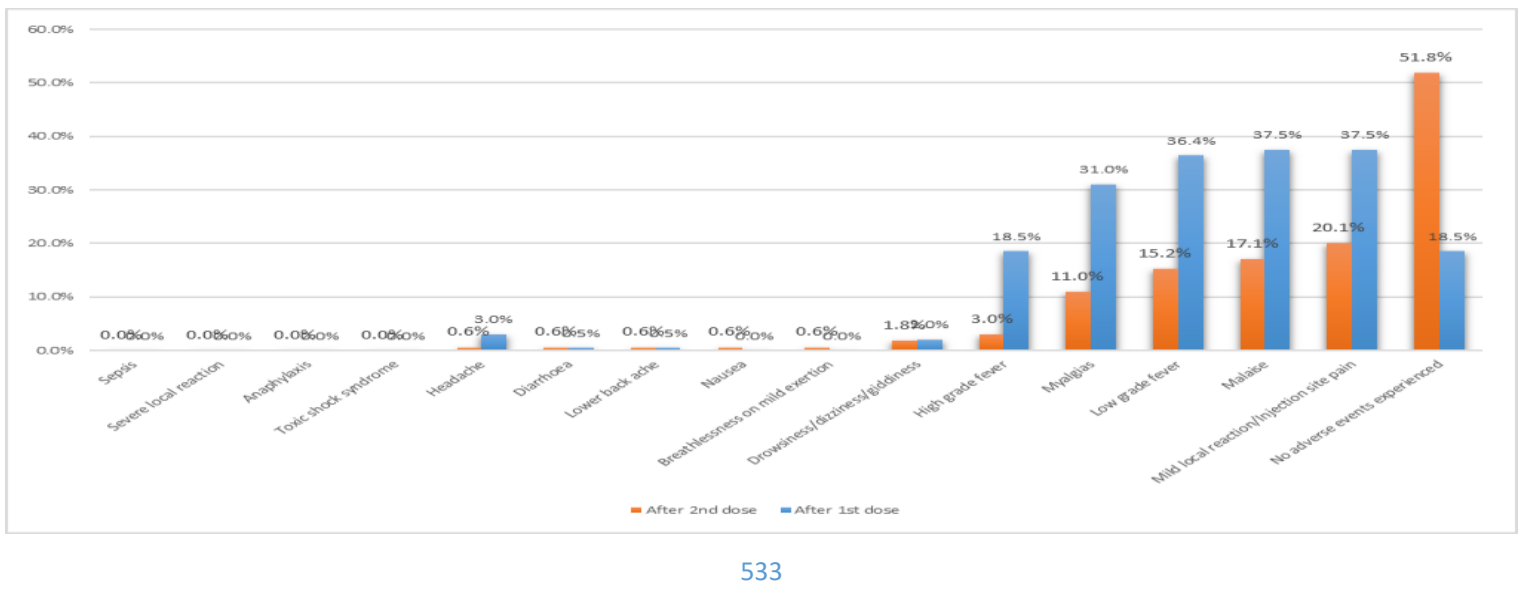

